\title{
The Influence of the Primary and Secondary Appraisals, and of the Big Five Personality Traits, on the Choice of Coping Strategies: A Study Based on Daily Stress
}

\author{
Iris Ferrer, Jordi Fernández-Castro (D), Sílvia Edo (D), Tatiana Rovira \\ Departament de Psicologia Bàsica, Eolutiva i de l'Educació, Universitat Autònoma de Barcelona, Bellaterra (Barcelona), \\ Spain
}

\begin{abstract}
The objective of this study was to assess the choice of coping strategies in relation to daily stress, taking into account the influence of the primary and secondary appraisals and the Big Five traits of personality. Over 10 days, a cohort of 122 individuals filled out an online diary in which they recorded the most important stressful event each day, their primary and secondary appraisals of this, and how they chose to cope with it. The results indicate that problem-focused coping depends on a strong primary and secondary appraisals, and on extraversion, whereas emotion-focused coping depends on a strong secondary appraisal and on extraversion. Social support seeking depends on strong primary and secondary appraisal, and on extraversion, openness and neuroticism. Refusal to seek support is associated with a strong primary appraisal, a weak secondary appraisal and a low level of conscientiousness. The conclusions are that momentary appraisals have a stronger predictive capacity than the personality traits, and that different coping strategies are not mutually incompatible.
\end{abstract}

Key words: daily stress, coping, primary appraisal, secondary appraisal, personality

\section{Introduction}

Daily stress involves irritating or disturbing events that occur during an individual's daily interaction with his/her environment (Kanner et al., 1981). Different studies have shown that the cumulative effects of daily stress on health may be even more important than the effects of major acute stressors. (Bolger et al., 1989; DeLongis et al., 1982; Wagner, Compas, \& Howell, 1988). Moreover, although daily stress does not always imply negative consequences, it sometimes contributes to setting in motion personal responses to successfully face and overcome difficulties (Almeida, 2005).

Correspondence concerning this article should be addressed to Jordi Fernández-Castro, Departament de Psicologia Bàsica, Eolutiva i de l’Educació, Universitat Autònoma de Barcelona, Bellaterra (Barcelona), Spain. E-mail: jordi.fernandez@uab.es

Received June 18, 2020 
The transactional model of stress (Lazarus \& Folkman, 1984) establishes that stress arises from the perception of an imbalance between demands and resources, as a result of primary appraisal, which refers to the importance and severity of the event, and secondary appraisal that refers to the resources available. The type of coping implemented is thought to be the key variable, which explains the emotional effects of stress, such that problem solving and positive reinterpretation are associated with positive emotions, whereas confrontation or self-blame are associated with unpleasant emotions (Folkman \& Lazarus, 1988).

It has been pointed out that stress is not faced by choosing between incompatible options, like for example, between solving the problem or restricting emotions, but rather, by adopting different approaches simultaneously, such as coordinating actions, conserving resources or adjusting expectations (Skinner et al., 2003). Furthermore, some strategies considered to be focused on emotions in fact involve focusing on the problem, such is the case of positive reinterpretation, while other strategies involve refusal, as in the case of self-blame (Carver \& Connor-Smith, 2010).

Given that daily stress is not something that can be identified at a specific moment but that develops and changes over time, it is particularly appropriate to study it using specific methodologies, such as ecological momentary assessment. This approach consists of capturing real time data at the individual's location using different mobile devices (Bolger, Davis, \& Rafaeli, 2003).

With regards to coping with daily stress events, it has been shown that when coping assessment is performed by asking individuals to remember the type of coping strategy used over a period of time, the responses do not coincide with the assessments that are made in real time (Stone et al., 1998).
The MoCope was developed taking these current concepts of coping into account. This questionnaire is a rapid system used for the momentary ecological evaluation of coping. It assesses the extent to which one tries to solve a problem, regulate emotions, seek social support or do nothing and ignore the problem, without considering these options to be mutually incompatible, or assuming a priori that one is more appropriate than the other (Rovira et al., 2016). The use of this instrument revealed that Emotional Intelligence is associated with a greater use of both acceptance and attempts to solve the problem, as well as the use of strategies aimed at regulating emotions and seeking social support, while it is also associated with less use of refusal strategies (Puigbó et al., 2018).

By contrast, there are studies that show how some personality traits influence daily stress, especially neuroticism (Bolger \& Schilling, 1991; Bolger \& Zuckerman, 1995), extraversion (Lee-Baggley, Preese, \& DeLongis, 2005; Newth \& Delongis, 2004) and perfectionism (Bartley \& Roesch, 2011; O'Connor et al., 2009). A meta-analysis carried out by Connor-Smith and Flachsbart (2007) on the relationship between personality variables and coping highlighted the positive relationship between problem-based coping and responsibility or extraversion, and between extraversion and social support seeking, as well as between neuroticism and emotion-based coping, refusal or avoidance. Neuroticism has also been linked to emotion-focused coping but encompassing, as it has been said above, both strategies of acceptance of emotion, as well as reinterpretation, and strategies of refusal of emotions as well as avoidance (Fornés-Vives et al., 2019).

In light of the evidence of the relationship between personality and daily stress, the question arises as to whether the choice of coping really depends on the individual's 
personality or on the moment-by-moment changes in the characteristics of each daily stressor, as defended in the transactional model since its outset (Lazarus \& Folkman, 1984). The question is, are the coping strategies adapted to each specific stressor or does each person have a general style of coping with different stressors in a similar way?

Taking into account that the proximal determinants of coping are the appraisal of the momentary stress, it is important to analyze how personality moderates this relationship. We have evidence in various studies of the relationships between personality and momentary measures of stress which indicate that personality does not have a direct effect but that its influence occurs through interactions with variable situations (Bolger \& Schilling, 1991; Gartland et al., 2014). However, we have not found studies that jointly evaluate both primary and secondary appraisals, and their interactions with the different personality traits.

Consequently, the objective of this study was to jointly assess the influence of the Big Five personality factors (Costa \& McCrae, 1992) and of the primary and secondary assessment on the choice of coping strategies adopted in resolving situations of daily stress. To achieve this objective, it is necessary to deploy a multilevel design in which the analysis of the repeated measures of the momentary appraisal of each individual is nested at a higher level defined by the personality traits of each participant.

In light of the above, it can be assumed that the choice of a specific coping strategy will depend on the relative importance of the primary and secondary appraisals, and of the predominant personality traits. As such, the following specific hypotheses were postulated:

1) Problem-focused coping will be more frequent in situations of strong perceived con- trol and it will be positively influenced by the conscientiousness trait.

2) Emotion-focused coping will be more frequent in situations of weak perceived control and it will be positively influenced by the neuroticism trait.

3) Social Support Seeking is more frequent in situations of weak perceived control and it will be positively influenced by the extraversion trait.

4) Refusal will be more frequent in situations of high importance and weak perceived control, and it will be positively influenced by the trait of neuroticism.

\section{Method}

\section{Sample and Procedure}

The study was carried out on a cohort of 122 people, 42 men (34.4\%) and 80 women $(65.6 \%)$. The mean age of the participants was 42.7 years (between 26 and 64 years old), with a standard deviation of 7.9 years. The selection was made using an Opt-in panel, representative of Spanish population.

The participants were selected by CERES, a market research agency, which randomly selected 345 people from the Toluna panel that is representative of the Spanish population and consists of 581605 people (60\% females; $30 \%$ from 18 to 24 years old, $27 \%$ from 25 to 34 years old, $22 \%$ from 35 to 44 years old, $14 \%$ from 45 to 54 years old, and $7 \%$ from 55 years or older). Toluna has an international community for social studies that has passed strict quality control, ensuring that there are no duplicate participants, that they are all real and there are no bots, that they do not answer an excessive number of surveys and that they answer at an adequate speed. The 345 selected panelists were asked to provide their signed informed consent, where they agreed to complete a ten-minute online diary before 
going to sleep for ten consecutive days. There were 148 initial surveys completed and 141 volunteers offered to participate in the daily study. A message was sent to the participants on each of the ten days (via e-mail, text message, and WhatsApp), mid-afternoon, with the link to the online diary, reminding them to fill this in before going to sleep. A total of 122 participants completed the diary for ten days and they received a compensation of 25 Euros for their participation in the study.

\section{Statistical Analysis}

The data were analyzed using the Mixed Models procedure of the SPSS software (version 26: IBM Corp, 2019) to examine the influence of personality traits and the cognitive appraisal on the coping strategies used to manage daily stress. Consequently, each model included 10 observations nested within individuals. As such, the data contained a two-level hierarchical structure: Level 1, the repeated daily assessment (primary and secondary appraisals), representing the within-person variation; and Level 2, the person variables (gender and personality traits), representing between-person variability. Level 1 predictors were group mean-centered, and these centered scores represent the deviation of a cognitive appraisal score from the person's generalized tendency.

Four separate analyses were made with each of the coping strategies as a dependent variable: problem-focused coping; emotion-focused coping; social support seeking -focused; and refusal. Four modelling analyses were conducted in each evaluation and the process fit for all of these modelling analyses commenced by establishing the simplest regression model (a random intercept model without explanatory variables), going from parsimonious to more complex models as recommended by Hox (2010). For each analysis, the explanato- ry variables were the primary appraisal and secondary appraisal (as level 1 variables), and gender and the traits of Neuroticism, Extraversion, Agreeableness, Openness, and Conscientiousness (as level 2 variables).

After the random intercept model (Model $1)$, the primary appraisal and secondary appraisal were introduced as fixed effects (Model 2). The primary appraisal and secondary appraisal were then introduced as aleatory effects (Model 3), and finally, gender and the traits of Neuroticism, Extraversion, Agreeableness, Openness, and Conscientiousness were introduced (Model 4).

A maximum-likelihood estimation (-2LL) was used to model the data at both levels. The significance of the change in -2LL was calculated based on a Chi Squared Distribution Table for the degrees of freedom in each model. The choice of the final model for each modelling analysis was made according to the last significant change in the maximum-likelihood estimation (-2LL).

\section{Measures}

\section{Baseline Questionnaire}

Participants completed a sociodemographic questionnaire followed by the following questionnaires, all in an online format.

The NEO Five-Factor Inventory (NEO-FFI). This inventory assesses five features of personality: Neuroticism, Extraversion, Openness, Agreeableness, and Conscientiousness (Costa \& McCrae, 1999). Each scale contains 12 items and the responses are given using a five-point Likert scale. In this study, the internal consistencies (Cronbach's $\alpha$ ) were 0.89 (Neuroticism), 0.86 (Extraversion), 0.77 (Openness), 0.67 (Agreeableness), and 0.83 (Conscientiousness).

The Perceived Stress Scale (PSS). This scale assesses the level of stress perceived over 
the last month. The Spanish version (Remor, 2006) of the original scale (Cohen, Kamarck, \& Mermelstein, 1983) was used. It contains 14 items and the responses are given using a 5-point Likert scale. In this study, the internal consistency was 0.89 (Cronbach's $\alpha$ ).

\section{Daily Diary}

All the participants completed an online diary at the end of each day on 10 consecutive days based on the Day Reconstruction Method (Kahneman et al., 2004), which reduces the retrospective bias of daily records. In this diary, the participants were first asked about their mood and then, after asking the participants to recall the main events that had occurred throughout the day, they were asked to think about the most important event they had experienced during the day and to use it as the reference to answer the following questionnaires:

The Daily Inventory of Stressful Events (Almeida, 1998). It is a classification of daily stressors that distributes them into the following categories: 1. I had a discussion or disagreement with someone. 2. I wanted to protest at something that happened to me, but I decided to let it pass to avoid a disagreement. 3. Something happened to me at work or with my studies. 4. Something happened to me at home. 5. I felt discriminated against because of my physical appearance, skin color, age or gender. 6 . Something happened to a close family member or friend that affected me. 7. Something else happened to me not included in the previous statements. Discomfort caused by stressors was also assessed using 7-point Likert-type scale.

The Primary Appraisal/Secondary Appraisal Scale (Gaab et al., 2005). The primary appraisal consists of the importance given to an event based on whether it is considered a threat, a challenge or a loss. The secondary appraisal is based on the perception of event control. Each appraisal is measured by 10 items using a 5-point Likert-type scale. Cronbrach's $\alpha=$ 0.81 was obtained for the Primary Appraisal Scale and Cronbach's $\alpha=0.79$ for the Secondary Appraisal Scale, in the application of these scales on the first day of this study.

The MoCope 10-item Coping Questionnaire (Rovira et al., 2016). This scale was specifically designed to be used in momentary ecological evaluation. It consists of a list of 10 coping items that can be performed at the time of the assessment, grouped into four categories that shared only functional properties, in line with the proposal about coping structure by Skinner et al., 2003. The four categories are Problem-focused coping ( 2 items: "I acted to solve it" and "I tried to come up with a plan on what to do"); Emotion-focused coping (3 items: "I accepted that things happen and cannot be changed", "I tried to find something positive in what happened" and "I sought to find a way to relax or disconnect"); Support-seeking ( 2 items. "I tried to ask someone for advice or help on what to do" and "I talked to someone about how I felt"), and Refusal (3 items: "I acted as if things have nothing to do with me", "I took my uneasiness out on others when I felt sad or angry" and "I criticized myself for what happened or I blamed myself for it."). These items were assessed using a 5-point Likerttype response scale. No time correlation between items is assumed, on the contrary, items from one category are more of an alternative, for example, accepting a problem can be manifested by acting or planning, and seeking support could be manifested by seeking emotional support or advice. For this reason, correlation between items is not a required condition for this assessment instrument. Since it is a momentary assessment scale a test-retest correlation is not required either. 


\section{Results}

Table 1 shows the aggregate descriptive statistics of the primary appraisal and the secondary appraisal, as well as the problem-focused, emotion-focused, social support seeking and refusal coping strategies. These aggregated data refer to the central trend of the above variables, without considering temporal variability. It can be noted that this data shows that the most common type of confrontation is emotions-focused, followed by problem-focused while seeking support and refusal are the least frequent.

\section{Problem-Focused Coping}

The intra-class correlation coefficients of Problem-focused Coping showed that $82.1 \%$ of the variation was at the moment level (level $1)$, whereas $17.9 \%$ was at the participant level (level 2). The multi-level analysis (see Table 2, left) showed that model $2(-2 \mathrm{LL}=4784.82)$, including the primary appraisal and secondary appraisal variables as fixed effects, resulted in a significant change in $-2 \mathrm{LL}\left(633.07^{* *}\right)$ relative to model 1 . With models 3 and 4 , which added primary and secondary appraisal as fixed/ random effects as well as gender and the five personality traits, there was a significant change in -2LL $\left(16.72^{* *}\right.$ and $\left.166.17^{* *}\right)$. No cross-level interactions were found between the variables from level 1 and 2, indicating that the primary appraisal was significant in terms of both the fixed $\left(0.06^{* *}\right)$ and random $\left(0.01^{* *}\right)$ effects, with slope differences between the participants. By contrast, the secondary appraisal was only significant in terms of the fixed effect $\left(0.23^{* *}\right)$, with no differences in the slopes between the participants. Problem-focused coping depends firstly on a strong secondary appraisal $\left(0.23^{* *}\right)$, followed by a strong primary appraisal $\left(0.06^{* *}\right)$ and strong Extraversion $\left(0.04^{* *}\right)$.

\section{Emotion-Focused Coping}

The intra-class correlation coefficients of Problem-focused Coping showed that $63.5 \%$ of the variation was at the moment level (level 1 ), while $36.5 \%$ was at the participant level (level 2). The multi-level analysis (see Table 2, right) showed that model $2(-2 L L=5402.47)$, including primary appraisal and secondary appraisal variables as fixed effects, resulted in a significant change in -2LL $\left(361.94^{* *}\right)$ relative to model 1 . With models 3 and 4 , which added primary appraisal and secondary appraisal as fixed/random effects as well as gender and the five personality traits, there was a significant change in $-2 \mathrm{LL}\left(42.37^{* *}\right.$ and $\left.175.63^{* *}\right)$.

Table 1 Mean and standard deviation, minimum and maximum of the quantitative variables for level 1

\begin{tabular}{lrcc}
\hline Variables & Mean & SD & Min-Max \\
\hline Primary Appraisal & 18.79 & 5.32 & $0-46$ \\
Secondary Appraisal & 20.50 & 3.80 & $0-32$ \\
Problem-focused Coping & 5.19 & 1.22 & $0-8$ \\
Social Support Seeking & 2.93 & 1.46 & $0-8$ \\
Emotion-focused Coping & 7.35 & 1.98 & $0-12$ \\
Refusal & 2.30 & 1.42 & $0-11$ \\
\hline
\end{tabular}

Note. SD = Standard Deviation, Min = Minimum, Max = Maximum. 


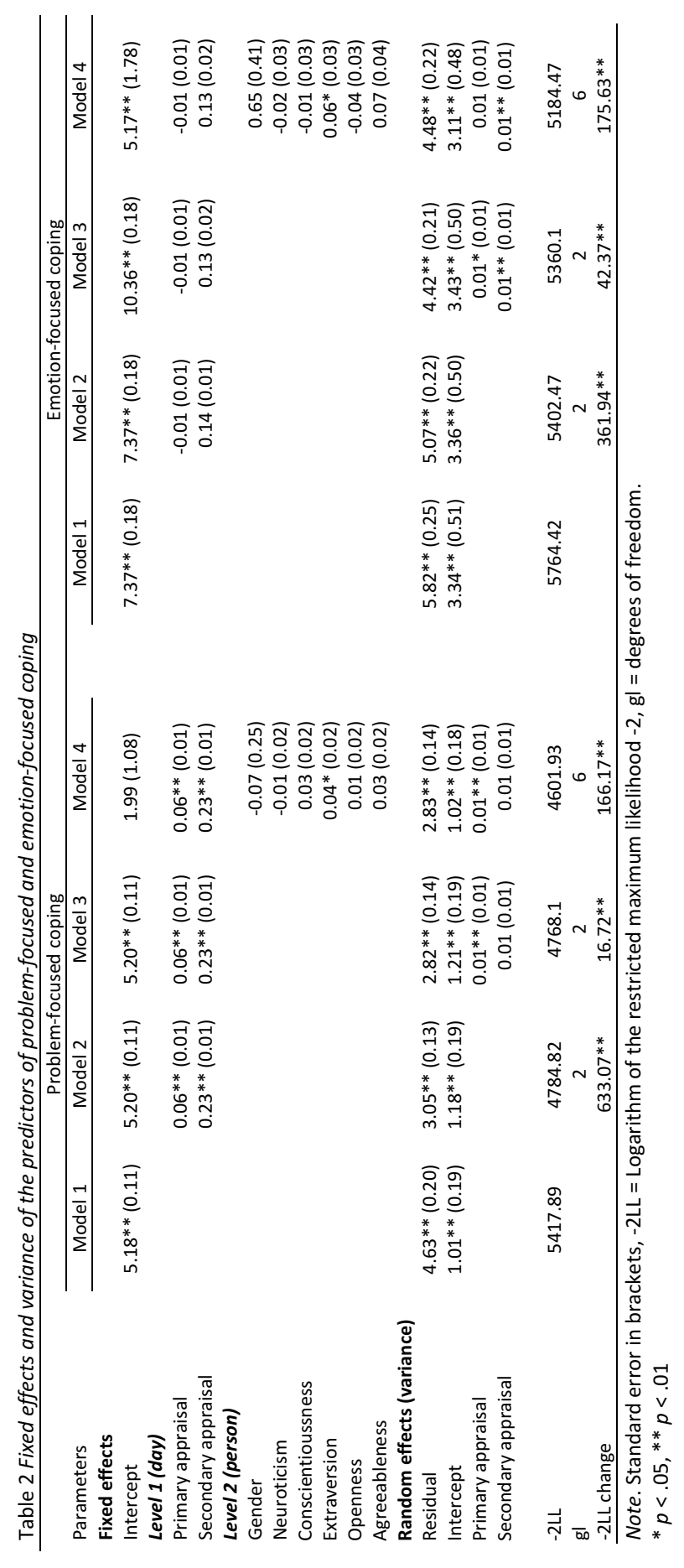


No cross-level interactions were found between the level 1 and 2 variables, indicating that only the positive influence of secondary appraisal on Emotion-focused coping was significant. The primary appraisal was not significant as a fixed effect $(-0.01)$ but it was significant as a random effect $\left(0.01^{*}\right)$, whereas the secondary appraisal was significant as both fixed $\left(0.13^{* *}\right)$ and random $\left(0.01^{* *}\right)$ effects, with slope differences between the participants for both appraisals. Extraversion $(0.06 *)$ positively influenced Emotion-focused coping and the slopes only differed between the participants in the secondary appraisal $\left(0.01^{* *}\right)$. Emotion-focused coping depends on a strong secondary appraisal $\left(0.13^{* *}\right)$ and strong Extraversion $\left(0.06^{*}\right)$.

\section{Social Support Seeking}

The intra-class correlation coefficients of Social Support Seeking showed that $77.1 \%$ of the variation resided at the moment level (level 1) while $22.9 \%$ lay at the participant level (level 2). The multi-level analysis (see Table 3, left) showed that model 2 (-2LL=5270.25), including the primary appraisal and secondary appraisal variables as fixed effects, resulted in a significant change in $-2 \mathrm{LL}\left(337.56^{* *}\right)$ relative to model 1 . With models 3 and 4 , which added primary appraisal and secondary appraisal as fixed/random effects, as well as gender and the five personality traits, there was a significant change in -2 LL (16.98** and $183.74 * *)$. No cross-level interactions were found between the level 1 and 2 variables, indicating that the primary appraisal was significant as a fixed $\left(0.11^{* *}\right)$ and random $\left(0.01^{* *}\right)$ effect, with a slope differences between the participants. By contrast, the secondary appraisal was only significant as a fixed effect $\left(0.03^{*}\right)$, with no differences in the slopes between participants. Extraversion $\left(0.06^{* *}\right)$, Neuroticism $\left(0.05^{* *}\right)$ and Openness $\left(0.04^{*}\right)$ all positively influenced social support seeking, which primarily depended on a strong primary appraisal $\left(0.10^{* *}\right)$, followed by strong Extraversion $\left(0.06^{* *}\right)$, strong Neuroticism $\left(0.05^{* *}\right)$, strong Openness $\left(0.04^{*}\right)$, and a strong secondary appraisal $\left(0.03^{*}\right)$.

\section{Refusal}

The intra-class correlation coefficients of Refusal showed that $70.3 \%$ of the variation was at the moment level (level 1), and $29.7 \%$ was at the participant level (level 2). The multi-level analysis (see Table 3, right) showed that model $2(-2 \mathrm{LL}=4997.44)$, including primary appraisal and secondary appraisal variables as fixed effects, resulted in a significant change in $-2 \mathrm{LL}\left(217.27^{* *}\right)$ relative to model 1 . With models 3 and 4, which added primary appraisal and secondary appraisal as fixed/ random effects as well as gender and the five personality traits, there was a significant change in -2LL (6.15* and $\left.168.66^{* *}\right)$. No cross-level interactions were found between the level 1 and 2 variables, indicating a positive influence of the primary appraisal and a negative influence of the secondary appraisal on Refusal. There were no differences in the slopes between the participants in both appraisals. Conscientiousness $\left(-0.05^{*}\right)$ negatively influences Refusal, which in turn depends on weak Conscientiousness $\left(-0.05^{*}\right)$, a weak secondary appraisal $\left(-0.04^{* *}\right)$ and a strong primary appraisal $\left(0.03^{* *}\right)$.

\section{Discussion}

In general terms, it should be highlighted that the intra-class correlations identified here indicate that the variables associated with the daily context, in this case the primary and secondary appraisals, explain more variability than those associated with the person, in this case the personality traits assessed. By 


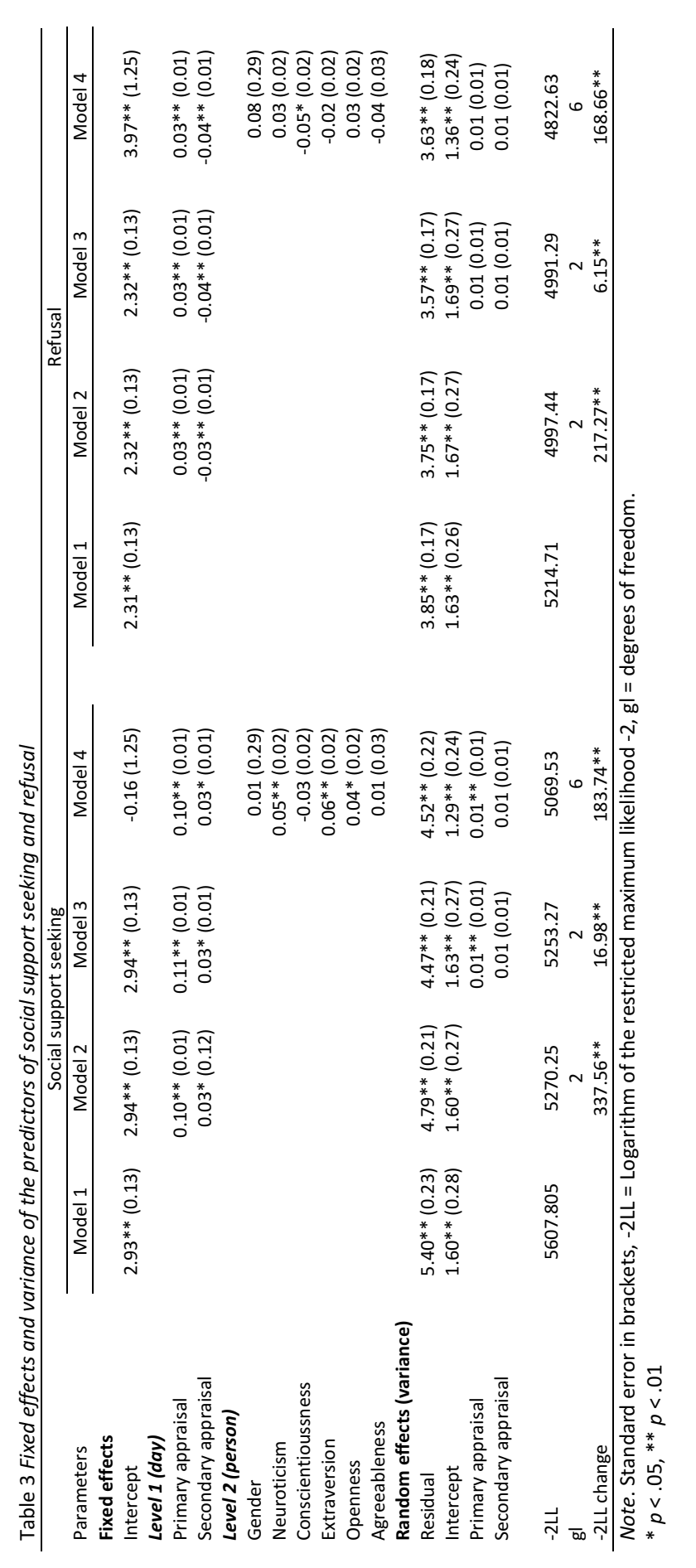


contrast, both the primary and secondary appraisals, and the personality traits, seem to directly influence the choice of coping strategies adopted, although no interaction has yet been found between these variables.

The fact that some random effects were found, especially in terms of the primary appraisal, indicates that while this has a clear influence on the general choice of the coping strategy, there are clear individual differences in terms of sensitivity to the primary appraisal, i.e. not all individuals react in the same way to an enhancement of the primary appraisal.

The first hypothesis of the study was partially confirmed. Indeed, when control is more strongly perceived it is more likely that a strategy is developed to resolve the problem but also, it is more important that attention is paid to the event. By contrast, the personality trait associated with problem-focused coping is not conscientiousness, as hypothesized previously (Gartland et al., 2014), but rather, extraversion. It was already seen in an earlier meta-analysis that both extraversion and conscientiousness were associated with problem-focused coping (Connor-Smith \& Flachsbart, 2007). We believe that these discrepancies are due to the fact that we have used an ecological momentary assessment approach, and that all Five of the Big personality traits were assessed (Costa \& McCrae, 1992; 1999) and not only conscientiousness.

The second hypothesis was not confirmed in this study as emotion-focused coping was not associated with situations of poor control, but rather, with the importance of the stressor, and it depends on the perception of resources that are available to cope with this. These findings contradict the traditional idea that emotion-focused coping is used in situations where there is little control because the problem cannot be directly resolved (Park, Armeli, \& Tennen, 2004). This discrepancy can be explained by the fact that a choice between problem-focused coping and emotion-focused coping was not necessarily made here, but rather, both could be recorded and each to a different extent. Alternatively, an emotion acceptance scale was used here, such that strategies of refusal to regulate emotions, and those of denial of the problem are included together in the refusal category. Therefore, it seems that if one is not forced to choose between problem-focused and emotion-focused coping, emotion-focused coping is more frequently registered, as observed previously (Puigbó et al., 2018). This may simply reflect the fact that there are situations in which the problem cannot be solved, whereas trying to regulate emotions is always possible. In terms of personality traits, emotion-based coping was previously most strongly associated with neuroticism (Connor-Smith \& Flachsbar, 2007). Here it was associated with extraversion, which could again reflect the fact that all personality traits were considered together, along with the primary and secondary appraisals.

The third hypothesis was only partially confirmed in this study, as seeking Social Support occurs when the stressor is perceived to be more important and more controllable. This is not consistent with our assumptions, although this phenomenon is associated with extraversion as previously hypothesized. Indeed, the conclusions of the earlier meta-analysis also highlighted an association between Extraversion and social support seeking (Connor-Smith \& Flachsbart, 2007). Moreover, a relationship was found between social support seeking and other personality traits, such as openness, a fact that is consistent with other findings (Lee-Baggley et al., 2005; O’Brien \& DeLongis, 1996), and also with neuroticism, which is not consistent with the findings from previous studies. This relationship with neuroticism, however, will need more attention in the future because it could be explained by the re- 
cent Krause, Pargament, and Ironson (2020) results, which found that strong support moderates the relationship between stress and anxiety, but only among highly extraverted study participants.

The fourth hypothesis postulated here was partially confirmed, as refusal occurs more frequently in important situations where little control is perceived, and it is not influenced by neuroticism although it is negatively affected by conscientiousness. The absence of a relationship between refusal and neuroticism is striking, and it might also be explained by the set of variables analyzed above. This phenomenon indirectly reinforces earlier results regarding the relevance of conscientiousness in coping with daily stress (Gartland et al., 2014), however, it is necessary to specify that a high perfectionism and a high level of self-demand can predict a high rate of avoidance more than neuroticism can (Dunkley, Mandel, \& Ma, 2014).

The assessment of both primary and secondary appraisals at any time is particularly important as it is common to assess the perceived control of stressors (for example see Park, Armeli, \& Tennen, 2004). However, having a high perception of the control of an event is not the same as considering the event to be more or less important, reflecting the importance of obtaining both measurements. Another consequence of assessing the appraisals is that their predictive ability at each moment is greater than that of the personality traits. In our opinion, this may explain why the results of this study are not consistent with those from previous studies on which our hypotheses were based, and that have in general attempted to directly relate personality and coping.

The data presented here offers a new vision of the perception of control. The hypothesis postulated was based on the assumption that the perceived control of the event led to at- tempts to resolve the problem, whereas no perception of control led to seek support, reducing the emotions or refusal to face the problem. With the tool used to assess the evolution of momentary coping, we found that secondary appraisal, that is the perception of control, facilitates different ways of coping with the situation that seem to be effective, whether they are problem-focused, emotion-focused or involve social support seeking. Alternatively, the failure to perceive control is specifically associated with refusal.

From a practical point of view, the present findings show the usefulness of using repeated daily diary methodologies to help clinical psychologist to predict future patients' reactions to daily stressors from their appraisals, as has been pointed out by Dunkley, Mandel, and Ma (2014). This could facilitate interventions to reduce maladaptive patterns based in refusal of both problems and emotions and build functional coping for vulnerable individuals.

This study has some important limitations. In the first place, the sample included a higher proportion of women than men because, although a random and gender-balanced sample was invited to participate in the study, more women voluntarily offered to participate. In addition, the study is based on self-report measurements that are not contrasted with objective or observational measurements. Nevertheless, the findings from this study provide some insights that will help to design future studies aimed at assessing whether combinations of problem-focused, emotion-focused and social support seeking-focused coping strategies are more effective than those involving a single choice.

\section{Acknowledgements}

The present work was supported by the Ministerio de Economía y Competitividad of Spanish Government [grant number FEDER, PSI2016-76411-R]. 


\author{
Authors' ORCID \\ Jordi Fernández-Castro \\ https://orcid.org/0000-0001-7725-3506 \\ Sílvia Edo \\ https://orcid.org/0000-0002-6564-3475 \\ Tatiana Rovira \\ https://orcid.org/0000-0003-1317-1282
}

\section{References}

Almeida, D. M. (1998). Daily Inventory of Stressful Events (DISE) expert coding manual. Division of Family Studies and Human Development. University of Arizona.

Almeida, D. M. (2005). Resilience and vulnerability to daily stressors assessed via diary methods. Current Directions in Psychological Science, 14(2), 64-68. https://doi.org/10.1111/j.0963-7214.2005.00336.x

Bartley, C. E., \& Roesch, S. C. (2011). Coping with daily stress: The role of conscientiousness. Personality and Individual Differences, 50(1), 79-83. https://doi.org/10.1016/i.paid.2010.08.027

Bolger, N., Davis, A., \& Rafaeli, E. (2003). Diary methods: Capturing life as it is lived. Annual Review of Psychology, 54, 579-616. https://doi. org/10.1146/annurev.psych.54.101601.145030

Bolger, N., DeLongis, A., Kessler, R. C., \& Schilling, E. A. (1989). Effects of daily stress on negative mood. Journal of Personality and Social Psychology, 57(5), 808-818.

Bolger, N., \& Schilling, E. A. (1991). Personality and the problems of everyday life: The role of neuroticism in exposure and reactivity to daily stressors. Journal of Personality, 59(3), 355-386.

Bolger, N., \& Zuckerman, A. (1995). A framework for studying personality in the stress process. Journal of Personality and Social Psychology, 69(5), 890-902. https://doi.org/10.1037/00223514.69.5.890

Carver, C. S., \& Connor-Smith, J. (2010). Personality and coping. Annual Review of Psychology, 61(1), 679-704.

Cohen, S., Kamarck, T., \& Mermelstein, R. (1983). A global measure of perceived stress. Journal of Health and Social Behavior, 24(4), 385-396.

Connor-Smith, J. K., \& Flachsbart, C. (2007). Relations between personality and coping: A meta-analy- sis. Journal of Personality and Social Psychology, 93(6), 1080-1107. https://doi.org/10.1037/0022 3514.93.6.1080

Costa, P. T., Jr. \& McCrae, R. R. (1992). The Revised NEO Personality Inventory (NEO-PI-R) and NEOFive-Factor Inventory (NEO-FFI) professional manual. Psychological Assessment Resources.

Costa, P. T., \& McCrae, R. R. (1999). NEO PI-R, Inventario de Personalidad NEO Revisado. NEOFFI, Inventario NEO reducido de Cinco Factores. Manual. TEA Ediciones.

DeLongis, A., Coyne, J. C., Dakof, G., Folkman, S., \& Lazarus, R. S. (1982). Relationship of daily hassles, uplifts, and major life events to health status. Health Psychology, 1(2), 119-136.

Dunkley, D. M., Mandel, T., \& Ma, D. (2014). Perfectionism, neuroticism, and daily stress reactivity and coping effectiveness 6 months and 3 years later. Journal of Counseling Psychology, 61(4), 616-633. https://doi.org/10.1037/cou0000036

Folkman, S., \& Lazarus, R. S. (1988). Coping as a mediator of emotion. Journal of Personality and Social Psychology, 54(3), 466-475. https://doi. org/10.1037/0022-3514.54.3.466

Fornés-Vives, J., García-Banda, G., Frias-Navarro, D., \& Pascual-Soler, M. (2019). Longitudinal study predicting burnout in Spanish nurses: The role of neuroticism and emotional coping. Personality and Individual Differences, 138, 286-291. https://doi.org/10.1016/i.paid.2018.10.014.

Gaab, J., Rohleder, N., Nater, U. M., \& Ehlert, U. (2005). Psychological determinants of the cortisol stress response: The role of anticipatory cognitive appraisal. Psychoneuroendocrinology, 30(6), 599-610. https://doi.org/10.1016/i.psyneuen.2005.02.001

Gartland, N., O'Connor, D. B., Lawton, R., \& Ferguson, E. (2014). Investigating the effects of conscientiousness on daily stress, affect and physical symptom processes: A daily diary study. British Journal of Health Psychology, 19(2), 311-328. https://doi.org/10.1111/bjhp.12077

Hox, J. J. (2010). Quantitative methodology series. Multilevel analysis: Techniques and applications (2nd ed.). Routledge/Taylor \& Francis Group. IBM Corp. (2019). IBM SPSS Statistics for Windows, Version 26.0. IBM Corp.

Kahneman, D., Krueger, A. B., Schkade, D. A., Schwarz, N., \& Stone, A. A. (2004). A survey 
method for characterizing daily life experience: The day reconstruction method. Science, 306(5702), 1776-1780. https://doi.org/10.1126/ science.1103572

Kanner, A., Coyne, J., Schaefer, C., \& Lazarus, R. (1981). Comparison of two modes of stress measurement: Daily hassles and uplifts versus major life events. Journal of Behavioral Medicine, 4(1), 1-39. http://link.springer.com/article/10.1007/ BF00844845

Krause, N., Pargament, K. I. \& Ironson, G. (2020). Assessing the relationships among spiritual social support, stress, and anxiety: Does extraversion also play a role in the coping process? Current Psychology, 39, 307-314. https://doi. org/10.1007/s12144-017-9764-8

Lazarus, R. S., \& Folkman, S. (1984). Stress, appraisal, and coping. Springer.

Lee-Baggley, D., Preece, M., \& DeLongis, A. (2005). Coping with interpersonal stress: Role of Big Five traits. Journal of Personality, 73(5), 1141-1180. https://doi.org/10.1111/i.1467-6494.2005.00345.x

Newth, S., \& Delongis, A. (2004). Individual differences, mood, and coping with chronic pain in Rheumatoid Arthritis: A daily process analysis. Psychology and Health, 19(3), 283-305. https:// doi.org/10.1080/0887044042000193451

O'Brien, T. B., \& DeLongis, A. (1996). The interactional context of problem-, emotion- and relationship-focused coping: The role of the Big Five personality factors. Journal of Personality, 64(4), 775-813. https://doi.org/10.1111/i.1467-6494.1996. tb00944.x

O’Connor, D. B., Conner, M., Jones, F., McMillan, B., \& Ferguson, E. (2009). Exploring the benefits of Conscientiousness: An investigation of the role of daily stressors and health behaviors. Annals of Behavioral Medicine, 37(2), 184-196. https:// doi.org/10.1007/s12160-009-9087-6

Park, C. L., Armeli, S., \& Tennen, H. (2004). Appraisal-coping goodness of fit: A daily internet study. Personality and Social Psychology Bulletin, 30(5), 558569. https://doi.org/10.1177/0146167203262855

Puigbó, J., Edo, S., Rovira, T., Limonero, J. T., \& Fernández-Castro, J. (2018). Influencia de la inteligencia emocional percibida en el afrontamiento del estrés cotidiano. Ansiedad y Estrés, 19(1), 1-6. https://doi.org/10.1016/i.anyes.2019.01.003

Remor, E. (2006). Psychometric properties of a European Spanish version of the Perceived Stress Scale (PSS). The Spanish Journal of Psychology, 9(1), 86-93.

Rovira, T., Ferrer, I., Edo, S., Fernández-Castro, J., Benavides, G., Doval, E., \& Martínez, F. (2016). Validity and feasibility of a nurses' coping questionnaire for its use in Ecological Momentary Assessment. European Health Psychologist, 18(Supplement), 758.

Skinner, E. A., Edge, K., Altman, J., \& Sherwood, H. (2003). Searching for the structure of coping: A review and critique of category systems for classifying ways of coping. Psychological Bulletin, 129(2), 216-269.

Stone, A. A., Schwartz, J. E., Neale, J. M., Shiffman, S., Marco, C. A., Hickcox, M., \& Cruise, L. J. (1998). A comparison of coping assessed by ecological momentary assessment and retrospective recall. Journal of Personality and Social Psychology, 74(6), 1670-1680.

Wagner, B. M., Compas, B. E., \& Howell, D. C. (1988). Daily and major life events: A test of an integrative model of psychosocial stress. American Journal of Community Psychology, 16(2), 189-205. 